\section{Commentary: Nothing will come of nothing: Surgical reimplantation for anomalous aortic origin of a coronary artery moves the field forward}

\author{
Julie A. Brothers, MD
}

Anomalous aortic origin of a coronary artery (AAOCA) is a congenital cardiac anomaly that is associated with sudden cardiac death in young athletic individuals. The subtypes of greatest clinical significance are interarterial, intramural anomalous aortic origin of the right coronary artery (AAORCA), and anomalous aortic origin of the left coronary artery. AAOCA can be managed through observation or surgery, depending on proximal coronary anatomy, symptoms, and provocative test results.

In this edition of the Journal, Bonilla-Ramirez and colleagues ${ }^{1}$ report on the surgical outcomes of interarterial, intramural AAOCA using the unroofing procedure or an alternate technique, transection and reimplantation (TAR), in a pediatric population. Between 2012 and 2019, the authors prospectively enrolled 61 patients, of whom 51 $(83.6 \%)$ had AAORCA. Sixteen patients $(26 \%)$ underwent TAR, 6 of whom had an unroofing attempt but were switched to TAR intraoperatively. The average age at repair was 15 years for TAR and 13 years for unroofing. The majority were male $(\mathrm{N}=39,63.9 \%)$, and $26(58 \%)$ had exertional symptoms. Operative complications in the TAR group included coronary stenosis requiring coronary artery bypass grafting $(\mathrm{CABG}, \mathrm{N}=1)$, pericardial effusion

\footnotetext{
From the Division of Cardiology, Children's Hospital of Philadelphia, Perelman School of Medicine at the University of Pennsylvania, Philadelphia, Pa.

Disclosures: The author reported no conflicts of interest.

The Journal policy requires editors and reviewers to disclose conflicts of interest and to decline handling or reviewing manuscripts for which they may have a conflict of interest. The editors and reviewers of this article have no conflicts of interest.

Received for publication Jan 4, 2021; revisions received Jan 4, 2021; accepted for publication Jan 5, 2021; available ahead of print Jan 19, 2021.

Address for reprints: Julie A. Brothers, MD, Division of Cardiology, Children's Hospital of Philadelphia, Perelman School of Medicine at the University of Pennsylvania, 3401 Civic Center Blvd, 8NW75, Philadelphia, PA 19104 (E-mail: brothersj@ chop.edu).

J Thorac Cardiovasc Surg 2021;162:1203-4

$0022-5223 / \$ 36.00$

Copyright (c) 2021 by The American Association for Thoracic Surgery

https://doi.org/10.1016/j.jtcvs.2021.01.013
}

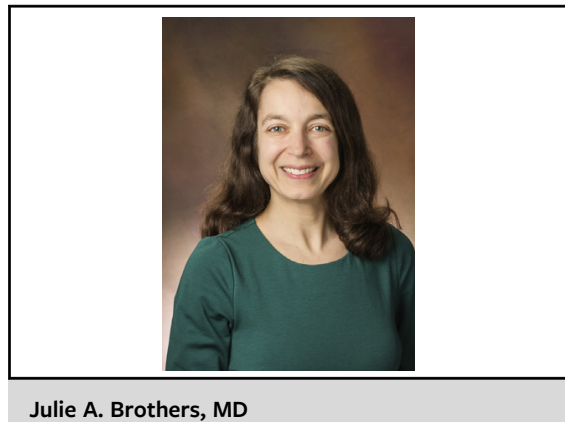

Julie A. Brothers, MD

CENTRAL MESSAGE

In certain cases, TAR is a reasonable alternative to the unroofing procedure for interarterial, intramural anomalous coronary arteries.

$(\mathrm{N}=1)$, and pancreatitis $(\mathrm{N}=1)$. Operative complications in the unroofing group included pericardial effusion $(\mathrm{N}=4)$ and wound dehiscence $(\mathrm{N}=1)$. After postoperative testing, 15 patients $(94 \%)$ in the TAR group and 42 patients $(93 \%)$ in the unroofing group were cleared for exercise.

The unroofing procedure was first described by Mustafa and colleagues ${ }^{2}$ in 1981 and is the most common procedure for intramural AAOCA. ${ }^{3}$ However, there may be situations in which a different technique is preferable. TAR may be considered when the proximal coronary courses below the commissure where commissure take-down and resuspension could result in aortic regurgitation. TAR also may be used if unroofing results in the proximal coronary arising from the wrong sinus or coursing behind the intercoronary pillar, leading to continued risk of sudden cardiac death.

TAR is not a new procedure. It was initially described in $2011,{ }^{5}$ with more recent outcomes reported in pediatric and adult patients. ${ }^{6-8}$ Unique to the article by Bonilla-Ramirez and colleagues ${ }^{1}$ is that they report solely on pediatric patients prospectively evaluated through a dedicated coronary anomaly program. The preoperative and postoperative assessments were uniform and thorough, including multiple imaging modalities and testing procedures. What is a strength is also a weakness. This is a single-center study with a relatively low number of TAR cases; collaboration with other centers would allow more robust evaluation of surgical outcomes. Follow-up was short- to midterm, and potential long-term complications, notably coronary ostial stenosis, warrant continued monitoring. Of note was the 
patient with AAORCA who underwent CABG after TAR in the immediate postoperative period. A similar outcome was reported by Gaillard and colleagues ${ }^{6}$ in a young child who underwent TAR, 2 angioplasties and stenting, and CABG 1 year later. This emphasizes that TAR is technically challenging with the potential for serious complications and should be performed only by experienced surgeons.

Indeed, as we learn more about the management of AAOCA, so too are we gathering data on different surgical techniques and the outcomes. This is of utmost importance in helping to determine if the risk of a specific operation outweighs the benefit. Only in this way are we able to move our field forward.

\section{References}

1. Bonilla-Ramirez C, Molossi S, Sachdeva S, Reaves-O'Neal D, Masand P, Mery CM, et al. Outcomes in anomalous aortic origin of a coronary artery after surgical reimplantation. J Thorac Cardiovasc Surg. 2021;162:1191-9.
2. Mustafa I, Gula G, Radley-Smith R, Durrer S, Yacoub M. Anomalous origin of the left coronary artery from the anterior aortic sinus. J Thorac Cardiovasc Surg. 1981;82:297-300.

3. Jegatheeswaran AS, Devlin PJ, Williams WG, Brothers JA, Jacobs ML, DeCampli WM, et al. Outcomes after anomalous aortic origin of a coronary artery repair: a Congenital Heart Surgeons' Society study. J Thorac Cardiovasc Surg. 2020;160:757-71.e5

4. Mery CM, De Leon LE, Molossi S, Sexson-Tejtel SK, Agrawal H, Krishnamurthy R, et al. Outcomes of surgical intervention for anomalous aortic origin of a coronary artery: a large contemporary prospective cohort study. $J$ Thorac Cardiovasc Surg. 2018;155:305-19.e4.

5. Goda M, Meuris B, Meyns B. Right coronary translocation for anomalous origin of right coronary artery from left coronary sinus. Interact Cardiovasc Thorac Surg. 2011;13:201-2.

6. Gaillard M, Pontailler M, Danial P, Moreau de Bellaing A, Gaudin R, du PuyMontbrun L, et al. Anomalous aortic origin of coronary arteries: an alternative to the unroofing strategy. Eur J Cardiothorac Surg. 2020;58:975-82.

7. Mainwaring RD, Murphy DJ, Rogers IS, Chan FP, Petrossian E, Palmon M, et al. Surgical repair of 115 patients with anomalous aortic origin of a coronary artery from a single institution. World J Pediatr Congenit Heart Surg. 2016;7:353-9.

8. Law T, Dunne B, Stamp N, Ho KM, Andrews D. Surgical results and outcomes after reimplantation for the management of anomalous aortic origin of the right coronary artery. Ann Thorac Surg. 2016;102:192-8. 